\title{
Neurosurgical education in Egypt and Africa
}

\author{
Nasser M. F. El-Ghandour, MD \\ Department of Neurosurgery, Faculty of Medicine, Cairo University, Cairo, Egypt
}

OBJECTIVE Africa still significantly lags in the development of neurosurgery. Egypt, located in North Africa, is welldeveloped in this specialty, with the largest number of neurosurgeons among all African countries. This article provides insight into neurosurgical training in Egypt, the challenges African neurosurgeons are facing, and the requirements needed to enhance neurosurgical education and build up the required neurosurgical capacity in Africa.

METHODS The information presented in the current work was collected from databases of the Egyptian Society of Neurological Surgeons and the World Federation of Neurosurgical Societies.

RESULTS There are two types of neurosurgical certification in Egypt. The first type is granted by the universities (MD), and the second is awarded by the Ministry of Health (Fellow of Neurosurgery). The program in both types ranges from 6 to 9 years. The number of qualified neurosurgeons in Egypt constitutes one-third of the total number of African neurosurgeons. There is a significant shortage of neurological surgeons in Africa, and the distribution is entirely unbalanced, with the majority of neurosurgeons concentrated in the North and South regions. The most important challenge facing neurosurgery in Africa is lack of resources, which is considered to be the main obstacle to the development of neurosurgery. Other challenges include the limited number of neurosurgeons, lack of training programs, and lack of collaboration among the different regions.

CONCLUSIONS Proper collaboration among the different regions within the African continent regarding neurosurgical education will enhance African neurosurgical capacity and make neurosurgery an independent specialty. The definite functional polarity among different regions, regarding both the number of qualified neurosurgeons and the neurosurgical capacity, is an important factor that could help in the development of neurosurgery in this continent.

https://thejns.org/doi/abs/10.3171/2019.12.FOCUS19804

KEYWORDS Africa; education; Egypt; neurosurgery; training

$\mathrm{E}$ GYPT, a North African country, has the largest number of neurosurgeons in Africa, and the neurosurgical specialty developed the earliest among all other African countries. The first neurosurgical practice was begun in 1949, whereas the first neurosurgical department was established in 1956. However, it was not until 1967 that the Egyptian Society of Neurological Surgeons (ESNS) was founded, and joined the World Federation of Neurosurgical Societies (WFNS) in 1969?

The development of neurosurgery in Egypt and the challenges Egyptian neurosurgeons face are subjects that should be well known. Obviously, the practice of neurosurgery in modern Egypt has shown rapid progression in the last 50 years. It is a successful model that can be replicated, adapted, and adopted in low- and middle-income countries. This article will briefly present the training programs available in Egypt, the current situation of this specialty in the African continent, the challenges African neurosurgeons are facing, and the requirements needed to enhance neurosurgical education in Africa and build up the required neurosurgical capacity in the Sub-Saharan region.

\section{Methods}

Information about the neurosurgical training programs, certification, and neurosurgical practice in Egypt was collected directly from the ESNS, the Supreme Council of Universities (SCU), and the Egyptian Ministry of Health. The number of neurosurgeons and the population in the different African countries was extracted from the "Global Neurosurgical Workforce Map," which is available on the website of the WFNS (www.wfns.org), according to the last update in 2016.

ABBREVIATIONS CAANS = Continental Association of African Neurosurgical Societies; E-learning = electronic learning; ESNS = Egyptian Society of Neurological Surgeons; SCU = Supreme Council of Universities; WFNS = World Federation of Neurosurgical Societies.

SUBMITTED October 15, 2019. ACCEPTED December 20, 2019.

INCLUDE WHEN CITING DOI: 10.3171/2019.12.FOCUS19804. 


\section{Results}

\section{Number of Neurosurgeons in Egypt/Africa}

It is notable that the number of neurosurgeons in one country such as Egypt almost equals the number of neurosurgeons that exist in East, West, and Central African countries combined; Egyptian neurosurgeons constitute about one-third of all African neurosurgeons. In contrast, many African countries do not have even a single neurosurgeon. The number of neurosurgeons and population in different African regions and the density of neurosurgeons per 100,000 in each country are shown in Tables $1-5$, according to the last updated information in 2016, available on the website of the WFNS.

\section{Neurosurgical Practice in Egypt}

There are 4 types of hospitals at which neurosurgical services are available in Egypt. The first type is university hospitals, which provide completely free healthcare service to anyone, in addition to education of medical students, which is also almost free. The second type is Ministry of Health hospitals, which are governmental hospitals that provide a very low-cost healthcare service. Some of these hospitals are insurance hospitals treating medically insured patients and some of them are educational hospitals that play a role in the education process. The third type is military hospitals that have very good resources and offer medical care to military personnel and their families.? The fourth type of hospital is private hospitals, which provide a very good medical service and are well equipped, but very expensive.

\section{Neurosurgical Certification in Egypt}

There are two types of neurosurgical certification in Egypt (Table 6). The first type is granted by the Egyptian universities through a training program developed by the SCU, which was implemented in 1978. This program consists of 2 parts. The first part is a full-time residency for 3 years, during which the candidate has to obtain the degree of Master's of Surgery/Neurosurgery (MS), which requires a 2-part examination in addition to a thesis in neurosurgery. The second part is spending a period ranging from 3 to 5 years in training, during which time the candidate has to obtain the degree of Doctor of Neurosurgery (MD), for which a thesis in neurosurgery has to be prepared and defended. In addition, a 2-part examination has to be passed. The first part is a written examination followed by oral/clinical examination 2 weeks later. The written examination format varies among different universities with a mixture of multiple-choice questions and essay questions. ${ }^{11}$

The oral/clinical examination includes anatomy, pathology, radiology, and examining patients through short and long cases. The Objective Structured Clinical Skills Examination is performed at most universities. The board of examiners comprises senior professors of neurosurgery, with a minimum of 5 years after being appointed to be professors. The average number of candidates is currently about 50 , the examination pass rate is about $60 \%$, and candidates usually succeed on the second or third attempt. ${ }^{11}$ Note that the examination is held 2 times every year, and
TABLE 1. Number of neurosurgeons and population in the region of North Africa

\begin{tabular}{lccc}
\hline Country & $\begin{array}{c}\text { No. of } \\
\text { Neurosurgeons }\end{array}$ & Population & $\begin{array}{c}\text { Neurosurgeon Density } \\
\text { per 100,000 People }\end{array}$ \\
\hline Algeria & 100 & $38,934,334$ & 0.256 \\
\hline Egypt & 400 & $89,579,670$ & 0.446 \\
\hline Libya & 11 & $6,258,984$ & 0.175 \\
\hline Morocco & 150 & $33,921,203$ & 0.442 \\
\hline Sudan & 41 & $39,350,274$ & 0.104 \\
\hline Tunisia & 73 & $10,996,600$ & 0.663 \\
\hline
\end{tabular}

Data were collected from the Global Neurosurgical Workforce Map 2016, available on the website of the WFNS.

attempts to succeed in the examination can be repeated every 6 months.

Documentation of the number of cases and outcomes extends throughout training; the candidate is given increasingly more demanding operations to perform under the supervision of a senior staff member. A formal logbook is obligatory in most Egyptian neurosurgical training centers. Fulfilling the necessary training criteria and passing the oral/clinical examinations leads to granting the degree of MD of neurosurgery. ${ }^{11}$

The second type of certification is granted by the Ministry of Health through a training program that extends from 7 to 9 years in qualified neurosurgical centers. ${ }^{11}$ This certificate confers the title of "Fellowship of Neurosurgery"; it is a training certificate and not an academic degree. The Ministry of Health ultimately determines who is eligible to join the program. The Ministry of Health offers a "Consultant Certificate," which is considered to be the license to practice neurosurgery for candidates offered the MD of neurosurgery from the Egyptian universities.

Regarding qualified neurosurgeons who are staff members in the departments of neurosurgery among Egyptian universities, after being granted the MD, they get appointed to the position of "Lecturer of Neurosurgery." According to the bylaws of the SCU, lecturers have to publish a certain number of articles in local and international journals; after a minimum period of 5 years they get promoted to the position of "Assistant Professor of Neurosurgery." After another period of 5 years, assistant professors will get promoted to the position of "Professor of Neurosurgery" if they fulfill a certain number of publications. Supervising a number of theses in master's and doctoral degrees is a requirement for both promotions, to ensure that neurosurgeons working in the universities are involved continuously in the research process.

\section{Neurosurgical Education in Egypt}

The ESNS is organizing 3 neurosurgical meetings each year. The main annual meeting usually takes place at the end of March and is called the "Egyptian Congress of Neurosurgery." This meeting is preceded by pre-Congress courses and hands-on workshops, with about 50-70 international faculty contributing to this meeting each year. There are another 2 interim meetings. The summer interim meeting is held in Alexandria, usually in collaboration 
TABLE 2. Number of neurosurgeons and population in the region of South Africa

\begin{tabular}{lcrc}
\hline \multicolumn{1}{c}{ Country } & $\begin{array}{c}\text { No. of } \\
\text { Neurosurgeons }\end{array}$ & Population & $\begin{array}{c}\text { Neurosurgeon Density } \\
\text { per 100,000 People }\end{array}$ \\
\hline Botswana & 10 & $2,219,937$ & 0.450 \\
\hline Namibia & 3 & $2,402,858$ & 0.124 \\
\hline South Africa & 33 & $54,058,647$ & 0.061 \\
\hline
\end{tabular}

Data were collected from the Global Neurosurgical Workforce Map 2016, available on the website of the WFNS.

with the Department of Neurosurgery of Alexandria University. The winter interim meeting is held in collaboration with 4 universities in Upper Egypt (Assiut, Aswan, Minia, and South Valley). In addition, there is a meeting for each university each year for 1-2 days. Courses in spine, skull base, neuroendoscopic, functional, pediatric neurosurgical, and endovascular surgery are held each year, many times in conjunction with one of the meetings. Accordingly, each month there are 1-2 neurosurgical events throughout the year. Many hands-on workshops take place in the different neurosurgical subspecialties, with international and local faculty working together, usually attended by young, recently qualified neurosurgeons in order to acquire more skills and experience (Fig. 1).

\section{Discussion}

\section{Challenges Facing Neurosurgery in Africa}

Limited Number of Neurosurgeons and Unbalanced Distribution

When compared with other continents, Africa has a real shortage of neurological surgeons. The practice of neurosurgery in the African continent shows a functional polarity, with the North and South more developed than the East, West, and Central regions; this polarity is an important factor that could help in the development of neurosurgery on this continent. Moreover, the distribution of neurosurgeons around the African continent is entirely unbalanced. The ratio of neurosurgeons to population is complex, with an evident disparity between the different regions..$^{10,11}$

The majority of neurosurgeons are located in only a few countries, with the remaining neurosurgeons distributed throughout the rest of the continent. ${ }^{8,10,11,13}$ Of the 1165 neurosurgeons in Africa, 756 are located in North African countries and South Africa, which results in a neurosurgeon to population ratio of 1:300,913. The remaining 409 neurosurgeons exist in East, West, and Central African countries, with a neurosurgeon to population ratio of $1: 2,237,016$.

It should also be noted that in countries with well-developed neurosurgery, most of the neurosurgeons exist in urban areas, whereas rural areas suffer from a shortage of neurosurgeons. ${ }^{3}$ This means that the quality of neurosurgical care will be expected to differ among different cities within the same country. However, offering complex neurosurgical care in central areas, while giving the priority to basic neurosurgical care in peripheral areas, remains a salient consideration in Africa. ${ }^{6}$
TABLE 3. Number of neurosurgeons and population in the region of East Africa

\begin{tabular}{lccc}
\hline \multicolumn{1}{c}{ Country } & $\begin{array}{c}\text { No. of } \\
\text { Neurosurgeons }\end{array}$ & Population & $\begin{array}{c}\text { Neurosurgeon Density } \\
\text { per 100,000 People }\end{array}$ \\
\hline Burundi & 1 & $10,816,860$ & 0.009 \\
\hline Comoros & 0 & - & - \\
\hline Eritrea & 1 & $4,790,000$ & 0.020 \\
\hline Ethiopia & 25 & $96,958,732$ & 0.025 \\
\hline Kenya & 22 & $44,863,583$ & 0.049 \\
\hline Madagascar & 6 & $23,571,713$ & 0.025 \\
\hline Malawi & 2 & $16,695,253$ & 0.011 \\
\hline Mozambique & 8 & $27,216,276$ & 0.029 \\
\hline Rwanda & 2 & $11,341,544$ & 0.017 \\
\hline Somalia & 4 & $10,517,569$ & 0.038 \\
\hline South Sudan & 0 & - & - \\
\hline Tanzania & 8 & $51,822,621$ & 0.015 \\
\hline Uganda & 10 & $37,782,971$ & 0.264 \\
\hline Zambia & 69 & $15,721,343$ & 0.438 \\
\hline Zimbabwe & 6 & $15,245,855$ & 0.039 \\
\hline
\end{tabular}

Data were collected from the Global Neurosurgical Workforce Map 2016, available on the website of the WFNS.

\section{Lack of Resources}

Neurosurgery has been overlooked and falsely considered to be a luxury all over the world. ${ }^{9}$ Neurosurgical care has not been considered a health priority, especially in the

TABLE 4. Number of neurosurgeons and population in the region of West Africa

\begin{tabular}{lccc}
\hline \multicolumn{1}{c}{ Country } & $\begin{array}{c}\text { No. of } \\
\text { Neurosurgeons }\end{array}$ & Population & $\begin{array}{c}\text { Neurosurgeon } \\
\text { Density per } \\
100,000 \text { People }\end{array}$ \\
\hline Benin & 6 & $10,598,482$ & 0.056 \\
\hline Burkina Faso & 6 & $17,589,198$ & 0.034 \\
\hline Cape Verde & 1 & 513,906 & 0.194 \\
\hline Congo Kinshasa & 21 & $4,504,962$ & 0.466 \\
\hline Cote d'Ivoire & 11 & $22,157,107$ & 0.049 \\
\hline Gambia & 2 & $1,928,201$ & 0.103 \\
\hline Ghana & 19 & $26,786,598$ & 0.070 \\
\hline Guinea & 4 & $12,275,527$ & 0.032 \\
\hline Guinea-Bissau & 12 & $1,800,513$ & 0.666 \\
\hline Liberia & 0 & - & - \\
\hline Mali & 10 & $17,086,022$ & 0.058 \\
\hline Mauritania & 6 & $3,969,625$ & 0.151 \\
\hline Niger & 8 & $19,113,728$ & 0.041 \\
\hline Nigeria & 30 & $177,475,986$ & 0.016 \\
\hline Senegal & 11 & $14,672,557$ & 0.074 \\
\hline Sierra Leone & 0 & - & - \\
\hline Togo & 4 & $7,115,163$ & 0.056 \\
\hline Dago & & &
\end{tabular}

Data were collected from the Global Neurosurgical Workforce Map 2016, available on the website of the WFNS. 
TABLE 5. Number of neurosurgeons and population in the region of Central Africa

\begin{tabular}{lccc}
\hline \multicolumn{1}{c}{ Country } & $\begin{array}{c}\text { No. of } \\
\text { Neurosurgeons }\end{array}$ & Population & $\begin{array}{c}\text { Neurosurgeon } \\
\text { Density per } \\
100,000 \text { People }\end{array}$ \\
\hline Angola & 7 & $24,227,524$ & 0.028 \\
\hline Cameroon & 7 & $22,773,014$ & 0.030 \\
\hline Chad & 3 & $13,587,053$ & 0.022 \\
\hline Congo Brazzaville & 4 & $74,877,030$ & 0.005 \\
\hline Gabon & 8 & $1,687,673$ & 0.474 \\
\hline
\end{tabular}

Data were collected from the Global Neurosurgical Workforce Map 2016, available on the website of the WFNS.

African continent. Without accessible neurosurgical care, easily treatable diseases will become high-risk diseases with high morbidity and mortality rates. ${ }^{5}$ African countries face a critical shortage of facilities and basic equipment required for neurosurgical procedures. ${ }^{5}$ Deficient infrastructure is considered to be a major challenge in Sub-Saharan Africa, and without the basic requirements such a specialty will never exist in those countries. Lack of resources is the main obstacle to building up neurosurgical capacity in Africa, whether it is equipment or training.

\section{Rapidly Increasing Population}

Another problem that is always overlooked is the very fast increase in the population in Africa, much more than in any other continent. In a country such as Egypt, the population doubles approximately every 30 years. This is another important issue, which means that the number of well-trained neurosurgeons has to be increased according to the rate of increase in the population, putting an extra burden on the process of training and education. This will also be naturally reflected in an increase in the pediatric age group, with an increased incidence of congenital abnormalities (such as myelomeningocele), hydrocephalus, and head injuries.

\section{Lack of Training Programs}

For years, African neurosurgeons used to undergo their training in other countries like Europe or the US; however, such type of training has two drawbacks. The first drawback is the maladaptation of these neurosurgeons when they come home to the specific conditions in their countries. ${ }^{8}$ Second, these neurosurgeons usually do not return home because of attractions (mostly financial) of practicing in such well-developed countries. Accordingly, there is a great need for the development of local neurosurgical training programs to overcome the problem of a shortage of neurosurgeons on the African continent. ${ }^{1}$

Many articles have been published that discuss the available training programs in Africa, ${ }^{1,11}$ mainly North African countries and South Africa. The average period of training in these programs is 6 years. An important initiative was the development of a fellowship training program in 2005 by 5 African countries (Ethiopia, Kenya, Rwanda, Tanzania, and Uganda), i.e., the College of Surgeons of Eastern, Central, and Southern Africa. ${ }^{10}$ Nevertheless, at present, many African countries do not have any local neurosurgical programs.

\section{Lack of Communication/Collaboration}

There is a definite problem in communication among the different neurosurgical societies within the African continent. There is also lack of accurate information about the exact number of neurosurgeons or society members, or communication data (such as email addresses or phone numbers), and this hinders the collaboration between the different countries and significantly hinders the development of neurosurgery. There is also the problem of language, with some countries speaking English (Anglophone countries) and others speaking French (Francophone countries), an important factor that tends to divide communication and collaboration in Africa.

\section{Lack of Governmental Awareness}

There are many African countries in which millions of citizens are not offered any neurosurgical care, and this situation is a result of poor advocacy for neurosurgery at the governmental level, rather than poverty. ${ }^{8}$ There is a sense of "unawareness" of the governments for the significance of this specialty; it is necessary to raise awareness of the deficient neurosurgical care as a global public health

TABLE 6. Types of neurosurgical certification in Egypt

\begin{tabular}{|c|c|c|}
\hline Certificate & Degree of Doctor (MD) of Neurosurgery & Fellowship of Neurosurgery \\
\hline Type & Academic degree & Clinical fellowship \\
\hline Granting institution & Egyptian universities & Ministry of Health \\
\hline Training program & $6-8$ yrs & $7-9$ yrs \\
\hline Examination & $\begin{array}{l}\text { Required (2 parts): master degree (MS) = } \\
\text { written exam, oral/clinical exam; doctor } \\
\text { degree (MD) = written exam, oral/ } \\
\text { clinical exam }\end{array}$ & $\begin{array}{l}\text { Required ( } 3 \text { parts): written exam (general } \\
\text { surgery \& basic science), written exam } \\
\text { (neurosurgery), oral/clinical exam } \\
\text { (neurosurgery) }\end{array}$ \\
\hline Essay/thesis & $\begin{array}{l}2 \text { theses required: master degree (MS), } \\
\text { doctor degree (MD) }\end{array}$ & 1 essay required: mini essay \\
\hline Applicants & $\begin{array}{l}\text { Mainly graduates on top of class from the } \\
\text { same university }\end{array}$ & $\begin{array}{l}\text { Medical graduates from Egyptian, African, } \\
\text { \& Arabic universities }\end{array}$ \\
\hline
\end{tabular}




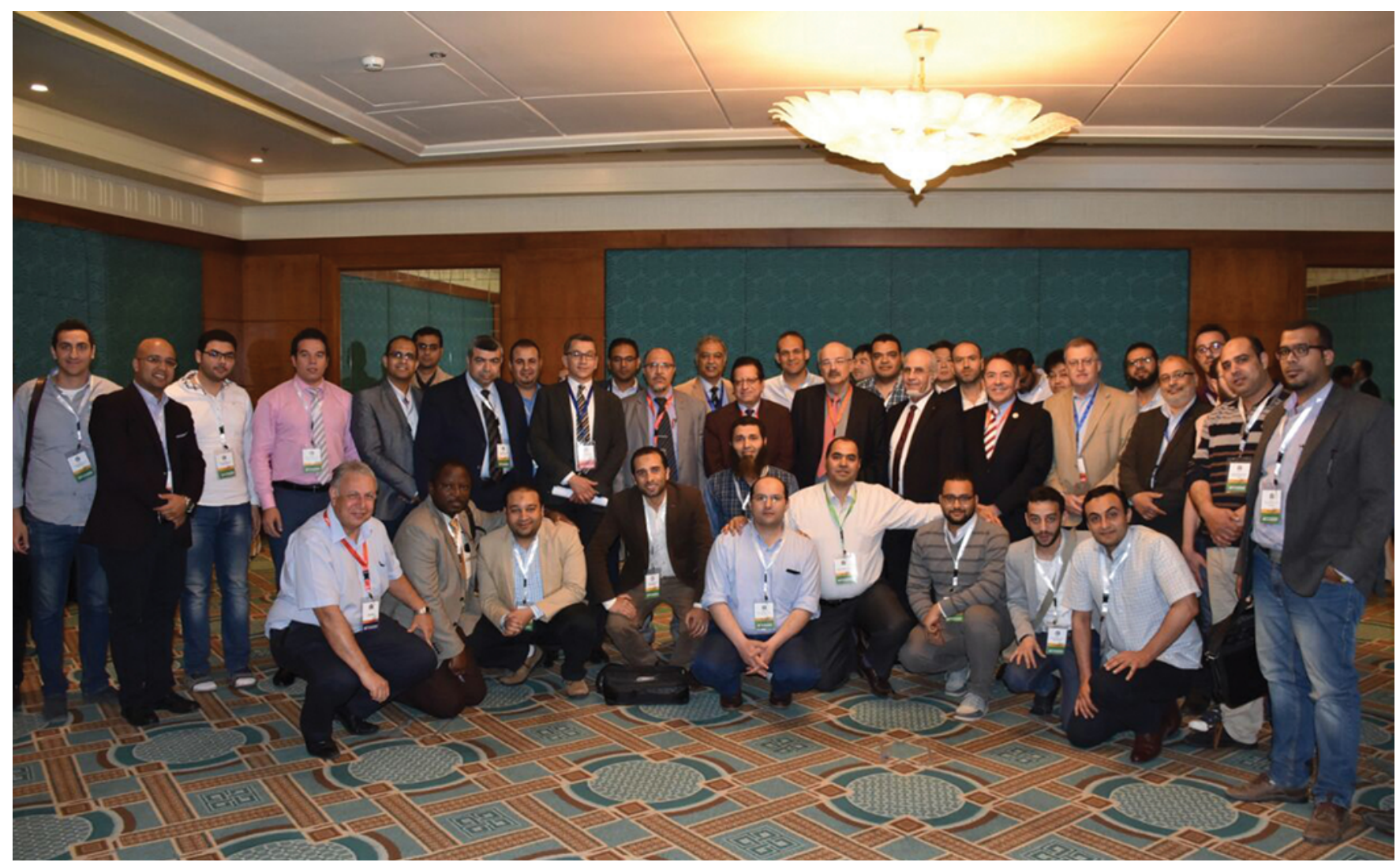

FIG. 1. Gathering photo of African neurosurgical candidates surrounding Prof. Franco Servadei, President of the WFNS (second row, seventh from right), and Prof. Nasser El-Ghandour, President of the ESNS (second row, eighth from the right), during a hands-on workshop about neuroendoscopy, organized under the auspices of the WFNS, held in conjunction with the 41st Egyptian Congress of Neurosurgery, March 21-24, 2018, at the Ritz-Carlton Hotel in Cairo, Egypt. Copyright Nasser M. F. El-Ghandour. Published with permission.

problem. Without financial support from governments, it will be impossible to build up or increase the neurosurgical capacity in Africa.

\section{Requirements to Improve Neurosurgery in Africa Education of Nonneurosurgeons}

Africa has a deficit of more than 8500 neurosurgeons; obviously, this deficit will not be filled in the near future. Accordingly, workforce optimization by training general surgeons, orthopedic surgeons, and pediatric surgeons to perform lifesaving and minor neurosurgical procedures, including treating traumatic brain injuries and congenital neurosurgical disorders, remains a priority to increase the neurosurgical capacity in Africa. Simple neurosurgical procedures will be treated in local district hospitals, whereas qualified well-trained neurosurgeons can allocate the necessary time to address complex and difficult neurosurgical cases. Similar efforts should be made in training nonneurosurgical personnel from other specialties (such as nursing, anesthesiology, and biomedical engineering). ${ }^{10}$

\section{Increasing Number of Neurosurgeons}

The development of neurosurgery in Sub-Saharan Africa depends mainly on increasing the number of neurosurgeons in those countries, ${ }^{2}$ which should proceed in conjunction with obtaining the needed equipment. The process of training is the keystone in the development of neurosurgery in those countries. North African countries (Egypt, Algeria, Morocco, and Tunisia) and South Africa should take the responsibility and play a crucial role in educating and training African neurosurgeons in other regions, and this should be organized by the Continental Association of African Neurosurgical Societies (CAANS), and supported by the WFNS and other international organizations.

An example of this collaboration is the Africa 100 project created by Prof. Majid Samii, which is designed to increase the number of qualified neurosurgeons in Africa. To be qualified in neurosurgery, the candidate has to join a training program in an African country with a welldeveloped neurosurgery program, such as the African WFNS training center in Rabat, Morocco, which plays an active role in training candidates (mainly from Francophone countries). As a further step, an important target will be the establishment of local neurosurgical training programs in Sub-Saharan Africa. ${ }^{6}$

\section{Postgraduate Education}

After increasing the number of neurosurgeons in the African continent, the next step will be acquiring skills 
and experience in the different neurosurgical subspecialties, which can be accomplished in different ways.

On-Site Training Approach. The development of neurosurgery in Africa largely depends on short-term visits made by individual neurosurgeons or surgical teams to Africa, consisting of regular conferences, courses, and hands-on workshops that take place in African countries, training local and regional neurosurgeons. The visit-based model can also benefit patients who are scheduled for surgery, as they can undergo operations by local neurosurgeons, side by side with experienced international neurosurgeons. ${ }^{14}$

Partnership or Twinning Model. Longitudinal partnerships between African neurosurgical centers and academic departments in advanced countries such as the US or European countries are beneficial. The training in this model depends on developing a long-term collaboration between both institutions, through either a single neurosurgeon visit or multidisciplinary teams. Not only neurosurgeons are trained, but also everyone who is involved in neurosurgical care delivery (e.g., nurses, anesthetists, and biomedical engineers). Regular visits by a neurosurgical team to the same center result in building a significant team relationship. ${ }^{16}$

The "twinning" program can also include visits of neurosurgeons from the African center to the developed academic medical center for acquiring skills and experience. There is an ongoing collaboration regarding training, mentoring, and research between the universities of Alabama, Miami, Toronto, Weill Cornell Medical College, and Duke, and neurosurgical centers in Latin America, Southeast Asia, and Sub-Saharan Africa. ${ }^{6,12}$

Online Neurosurgical Education. Distance electronic learning (E-learning) is growing as a teaching tool and is becoming used in the field of medicine. ${ }^{15}$ E-learning refers to all organized learning activities conducted by an educational organization with the help of information and communications technology. This model comprises webinars, electronic libraries, and online courses. ${ }^{4}$ It aims to provide course material in an easy and friendly way, in which faculty and residents can communicate online at the same time, or they can enter the course site and view the material at different times. ${ }^{14}$ The online neurosurgical education can be used in Africa as a cost-effective alternative to the face-to-face learning process offered by a visitbased model or by the twinning model.

\section{Overcoming Problems in Communication}

The author of this article was honored to create the e-hotline service for CAANS, which was activated in September 2019. The new e-hotline is http://2013.tel or www.2013.tel, in which 2013 refers to the year that Prof. Majid Samii, the WFNS ambassador to Africa, gathered all the African neurosurgical leaders in Nairobi, and it was agreed that all African organizations would be united as a single African organization under the name of CAANS.

The e-hotline is the most recent and fastest method of communication known worldwide. By typing 2013.tel in the browser of the smart phone (either Android or iPhone), or in the browser of a notebook computer, in a few seconds the page will be opened and a group of icons will be found. This is the electronic gate to all icons of the CAANS.

One should not be confused between the e-hotline and the website. The website of the CAANS (www.caans2013. org) is represented by one of the icons, and clicking this icon will open the website. The system is simple, easily used, and fast, works on all types of smart phones, and works in both English and French languages so that it can be suitable for both Anglophone and Francophone countries. The e-hotline can enhance the process of education by bringing all African neurosurgeons together into a common information technology platform. This facilitates arranging educational courses and meetings, and their dissemination. It can also enhance the process of E-learning through active webinars and live broadcasts of neurosurgical lectures.

\section{Increasing Awareness of Governments/Resources}

It is very important to highlight the significance of our specialty to governments, and that is the role of local neurosurgical societies. ${ }^{1}$ An important link should exist between national neurosurgical societies and local authorities; an important coordination and collaboration should exist between neurosurgical organizations and institutions of civil society, which can facilitate donations and funds needed for training or equipment. Nongovernmental organizations should be engaged in the process of neurosurgical education.

Collaboration with vital components such as the National Surgical, Obstetric, and Anesthesia Plans, or the United Nations Sustainable Development Goals, is very important. Unless such collaboration exists, the neurosurgical specialty will remain an isolated impotent community. Neurosurgical education has to be coordinated with the work of other specialties and by the action of other groups such as the Global Industry Classification Standard, the G4 Alliance, and the WHO-WFNS liaison committee.

\section{Establishing Common Certification}

The presence of different training programs among the African countries will definitely result in qualifying neurosurgeons with different standards; this is the result of variations in the curriculum, number of training years, training facilities, quality of examiners, and the format of examinations. There is a gap between well-established programs in North and South Africa, and the newly developed training programs in other regions. As a result, many neurosurgeons are adequately trained, whereas others are not. ${ }^{11}$ An important objective is bringing all these programs together to share and harmonize training standards to develop a unified curriculum, leading to a common certification (the African Board of Neurosurgery). This process will bring African neurosurgery into a common platform that would be equivalent to the best international neurosurgical certifications, reducing inequalities in neurosurgical care, enhancing neurosurgical education, and increasing neurosurgical capacity in the African continent.

\section{Conclusions}

Neurosurgical education in Africa is far from adequate; 
this continent continues to significantly lag in the development of this specialty. There are many reasons for this, including lack of resources, which is considered to be the main obstacle to the development of neurosurgery in Africa. Other obstacles include the limited number of neurosurgeons, lack of training programs, and lack of collaboration among the different regions. There is definite functional polarity, with the North and South more developed than other regions regarding both the number of qualified neurosurgeons and the neurosurgical capacity. Egypt is considered to be well-developed in neurosurgical care, equipment, and training programs, and Egyptian neurosurgeons constitute one-third of the total number of African neurosurgeons. In contrast, other countries in Africa do not have a single neurosurgeon. Proper collaboration among the different regions within the African continent regarding neurosurgical education will enhance African neurosurgical capacity and make neurosurgery an independent specialty; the CAANS should endeavor to support and strengthen such collaboration.

\section{Acknowledgments}

As a President of the ESNS, I would like to thank all Egyptian neurosurgeons who supplemented me with valuable information. As General Secretary of the CAANS, I would like to thank all the board members for their cooperation and support. As Second Vice-President of the WFNS, I would like to thank the WFNS for creating the Global Neurosurgical Workforce Map available on the website, which was an excellent source of information for me. My thankfulness also goes to all the junior neurosurgeons for giving me feedback about the challenges facing neurosurgery in Egypt and Africa.

\section{References}

1. Adeloye A: Neurosurgical education in Africa. Neurosurgery 10:130-132, 1982

2. Albright AL: Reflections on developing pediatric neurosurgery in Sub-Saharan Africa. J Neurosurg Pediatr 18:127138, 2016

3. Albright AL, Ferson SS: Developing pediatric neurosurgery in a developing country. J Child Neurol 27:1559-1564, 2012

4. Blankstein U, Dakurah T, Bagan M, Hodaie M: Structured online neurosurgical education as a novel method of education delivery in the developing world. World Neurosurg 76:224-230, 2011

5. Butler MW: Developing pediatric surgery in low- and middle-income countries: An evaluation of contemporary education and care delivery models. Semin Pediatr Surg 25:43-50, 2016
6. Dewan MC, Rattani A, Fieggen G, Arraez MA, Servadei F, Boop FA, et al: Global neurosurgery: the current capacity and deficit in the provision of essential neurosurgical care. Executive Summary of the Clobal Neurosurgery Initiative at the Program in Global Surgery and Social Change. J Neurosurg 130:1055-1064, 2019

7. El Gindi S: Neurosurgery in Egypt: past, present, and futurefrom pyramids to radiosurgery. Neurosurgery 51:789-796, 2002

8. El Khamlichi A: African neurosurgery: current situation, priorities, and needs. Neurosurgery 48:1344-1347, 2001

9. Ellegala DB, Simpson L, Mayegga E, Nuwas E, Samo H, Naman N, et al: Neurosurgical capacity building in the developing world through focused training. J Neurosurg 121:15261532, 2014

10. Fuller A, Tran T, Muhumuza M, Haglund MM: Building neurosurgical capacity in low and middle income countries. eNeurologicalSci 3:1-6, 2015

11. Gasco J, Barber SM, McCutcheon IE, Black PM: Neurosurgery certification in member societies of the WFNS: Africa and the Middle East. World Neurosurg 76:18-27, 54-56, 2011

12. Haglund MM, Kiryabwire J, Parker S, Zomorodi A, MacLeod D, Schroeder R, et al: Surgical capacity building in Uganda through twinning, technology, and training camps. World J Surg 35:1175-1182, 2011

13. Hyder AA, Sugerman DE, Puvanachandra P, Razzak J, ElSayed H, Isaza A, et al: Global childhood unintentional injury surveillance in four cities in developing countries: a pilot study. Bull World Health Organ 87:345-352, 2009

14. Liang KE, Bernstein I, Kato Y, Kawase T, Hodaie M: Enhancing neurosurgical education in low- and middle- income countries: current methods and new advances. Neurol Med Chir (Tokyo) 56:709-715, 2016

15. Masic I: E-learning as new method of medical education. Acta Inform Med 16:102-117, 2008

16. Riviello R, Ozgediz D, Hsia RY, Azzie G, Newton M, Tarpley $\mathrm{J}$ : Role of collaborative academic partnerships in surgical training, education, and provision. World J Surg 34:459465,2010

\section{Disclosures}

The author reports no conflict of interest concerning the materials or methods used in this study or the findings specified in this paper.

\section{Correspondence}

Nasser M. F. El-Ghandour: Cairo University, Cairo, Egypt. elghandour@yahoo.com. 